\title{
Diversity, Body Mass, and Latitudinal Gradients in Primates
}

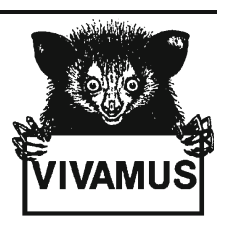

\author{
A. H. Harcourt • B. M. Schreier
}

Received: 27 September 2008 / Accepted: 18 December 2008 /

Published online: 10 February 2009

(C) The Author(s) 2009. This article is published with open access at Springerlink.com

\begin{abstract}
We examined latitudinal gradients in central value and diversity of body mass of primates to increase understanding of the Forster effect (decrease in taxonomic diversity with increasing latitude) and the Bergmann effect (increase of body mass with latitude). Data are from the literature. We used species' median body mass of females and mid-latitude $(N=164)$. We account for phylogenetic effects with comparative analysis by independent contrasts and analysis at differing taxonomic levels. Globally, diversity of both taxonomy and body mass declined significantly with increasing latitude. The decrease in the range of body masses with increasing latitude was caused mainly by the absence of several small-bodied clades at higher latitudes, but also by the absence there of great apes. The disappearance of the smallbodied clades caused an increase in median body mass with latitude, i.e., primates show a significant taxon-wide Bergmann effect, including with phylogenetic correction. Within the Primates, the Bergmann effect was significant within taxa that extend from the equator the farthest into temperate regions: the Old World infraorder Catarrhini, family Cercopithecidae, and subfamily Cercopithecinae; the Asian Cercopithecidae; and in Southeast Asian Sunda, Macaca. The results accord with hypotheses for the Forster effect that latitudinal gradients in taxonomic diversity result from high rates of speciation in the tropics, and ecological, and therefore evolutionary, constraints on diversity at higher latitudes. For the Bergmann effect, the results support energetic hypotheses that the very largest-bodied and the small-bodied taxa cannot survive the long periods of limited resources at higher latitudes.
\end{abstract}

\footnotetext{
A. H. Harcourt $(\bowtie) \cdot$ B. M. Schreier

Department of Anthropology \& Graduate Group in Ecology, University of California,

Davis, CA 95616, USA

e-mail: ahharcourt@ucdavis.edu

Present address:

B. M. Schreier

California Department of Water Resources, Sacramento, CA 95814, USA
} 
Keywords biodiversity $\cdot$ biogeography $\cdot$ body size $\cdot$ macroecology

\section{Introduction}

Of the many latitudinal gradients posited to exist, researchers have probably studied the taxonomic latitudinal gradient the most extensively and for the longest time. Nevertheless, debate still continues about the evolutionary and ecological processes that might produce the usual diminution of taxonomic richness and diversity with increasing latitude (Hillebrand 2004). For brevity's sake, we here term that gradient the Forster effect (Forster 1778). For some of the other latitudinal gradients, even their reality is still debated (Meiri and Dayan 2003).

Comparisons of macroecological gradients can shed light on the processes that produce each gradient. The implication of a change of taxonomic diversity with latitude must be that morphological diversity also changes, given that taxa are still largely described by morphology. However, latitudinal gradients in morphological diversity have been sparsely investigated in comparison to the efforts invested in analysis of latitudinal gradients in taxonomic diversity (Green et al. 2008). Where they have been investigated, the link between taxonomic and morphological diversity is not necessarily tight (Roy et al. 2004; Shepherd 1998).

Our first aim, therefore, is to compare a latitudinal gradient in taxonomic diversity with the pattern of change with latitude of morphological diversity in a well-studied tropical taxon to understand better the processes that might produce the Forster effect. Most analyses of the Forster effect relate taxonomic diversity to various aspects of the physical environment, such as evapo-transpiration rate, as a means of understanding the process of change in diversity with latitude. Another approach is to compare taxa that differ in whether they show the Forster effect or not (Hillebrand 2004). A third approach, the one we adopt here, is to compare how low- and highlatitude taxa differ in a particular morphological trait (Blackburn and Gaston 1996; Cardillo 2002). The morphological trait that we chose is body mass, because it is the trait for which most data are available, and because it correlates with so many aspects of species' biology.

Hillebrand's (2004) major review of the existence of the Forster effect and its biological correlates identified body mass as a significant correlate of strength and slope of the taxonomic gradient with latitude: larger-bodied taxa showed a stronger, steeper gradient. Any analysis of body mass and latitudinal gradients, especially overall change of body mass with latitude, necessarily raises the topic of the Bergmann effect, i.e., the tendency for related taxa to have larger body mass at higher latitude (Blackburn et al. 1999). Researchers have debated at length the existence of the Bergmann effect and its explanations (Ashton et al. 2000; Meiri and Dayan 2003). Nevertheless, where a gradient of mass with latitude is found, it significantly more often than not shows the Bergmann effect (Ashton et al. 2000; Meiri and Dayan 2003). [We follow precedence (Gaston et al. 1998), and write of the Bergmann effect, not rule, because the relationship is far from universal.]

However, as is the case for macroecology as a whole, analyses of the Bergmann effect have concentrated on temperate taxa, despite the demonstrable greater taxonomic diversity of the tropics. For example, Meiri and Dayan (2003) could 
find for their review of the Bergmann effect across mammals only 36 tropical species of the 147 species in their survey for which we could identify provenance.

Analyses of the Bergmann effect are mostly of the Rensch variation, i.e., intraspecific (Gaston et al. 2008). The same is true of the relatively few tropical taxa that have been studied. However, whether a particular organism is termed a species or a subspecies changes, so some past intraspecific analyses might now be interspecific ones. As is the case with temperate taxa, the tropical taxa more often than not show the Bergmann effect. Thus in Meiri and Dayan's (2003) review of the Bergmann effect within mammalian species, $69 \%$ of the 36 tropical species in their analysis showed the effect.

The order Primates is an unusually well known tropical taxon, and perhaps the best known taxon of tropical forest mammals (Harcourt 2006). It is therefore an appropriate taxon for macroecological analyses of the tropics: we here analyze latitudinal change in taxonomic and morphological diversity.

In primatology, the few analyses of the Bergmann effect are mostly of the Rensch variation. Most of the intraspecific comparisons demonstrate the effect, if not all of them statistically, but some do not (Albrecht et al. 1990; Ashton et al. 2000; Meiri and Dayan 2003). Most studies are of macaque, Macaca, species. Researchers have reported quantitative analyses of the effect across species for only macaques (Fooden 1971a, b).

Here, therefore, we investigate the Bergmann effect across species globally, and within continents. We do so across the order Primates as a whole, and also within subtaxa of primates, down to comparisons across species within genera.

Hawkins and Diniz-Filho (2004) have criticized analyses of correlations of richness with latitude as confusing and obsolete. They argue that measures of exact environmental changes, such as temperature or energy input, should be used, along with more complete 2-dimensional spatial analyses. We nevertheless used only latitude. In the absence of knowledge of even whether a Bergmann effect exists in the Primates, let alone of the precise influential environmental variable or its process of operation, it is premature to insist on investigation of particular environmental variables. Instead, latitude is a convenient, single index of the multitude of environmental changes that occur globally from the equator to the poles against which we can compare both taxonomic and morphological change (Blackburn et al. 1999). Further, it is possible that latitude might represent better than do present environment variables the totality of past and present environments that have influenced the present distribution of a taxon.

\section{Methods}

Data

Our sample consisted of 164 species — about half the total — from 48 genera and 13 families/subfamilies for which data were available for both latitude and body mass. The data are from the literature. Though we used original literature for body mass, $<10 \%$ of our species differed by $>10 \%$ in body mass from Smith and Jungers' (1997) detailed compendium, which is therefore the most convenient source for 
readers. Sources for the geographic ranges from which we calculated mid-latitudes are listed in detail in Harcourt (2000).

We used body mass of females to avoid potential complications of differences between taxa in degree of sexual dimorphism in size. The value for mass that we used was the median of all studies that we found; we employed only field studies, unless the only data available were from captivity. Bromham and Cardillo (2007) have shown that island species and subspecies of primates, most of them Asian, are generally smaller than the mainland forms. The finding produces a potential confound into our analysis, if islands cluster at lower latitudes, as they do in Asia. However, of the 9 pairs of species and mainland forms for which Bromham and Cardillo showed the island form to be smaller, only in 5 of our sample was the island form smaller, and in one of those, that smaller island form was not at lower latitude. The 4 showing the island effect of diminutive size were all Asian. Our Asian sample was 55 species. We suggest that 4 species of 55 showing the island effect produces a negligible bias.

We used latitudinal midpoint to characterize a taxon's latitude, rather than presence in a latitudinal band. A benefit of using latitudinal midpoint is that each taxon is represented only once in the analyses, so obviating the statistical problems of intrinsic spatial autocorrelation that can arise with the use of latitudinal bands, even if other analytical problems remain (Blackburn and Hawkins 2004). A disadvantage can be bias toward low latitudinal midpoints in taxa with large ranges. However, in primates as in many other organisms, species with large geographic ranges are a minority of the data. Thus, only 15 species have a range larger than midrange, i.e., the range size midway between the largest and smallest range, leaving 149 with a range size smaller than the midrange.

Mid-latitude is the middle of the north-south maxima for each species. We also analyzed via ArcGIS 3.1 (ESRI Inc. 1998) a midpoint weighted toward the center of the bulk of each species' range. However, with the weighted measure, no significant result from the unweighted measure became nonsignificant, and no nonsignificant result became significant. Therefore, we present results for only the simpler measure.

Recent taxonomic change has considerably increased the number of primate species potentially recognized, mostly as a consequence of the raising of subspecies to the level of species with application of the phylogenetic species concept (Groves 2001). Because little is currently known about the biology of some of these potential new species, we in effect implemented the concept of superspecies or geospecies (Grubb et al 2003), and used mostly Groves' (1993) taxonomy.

The phylogeny used is that of Purvis (1995), with various previously described alterations (Harcourt et al. 2005), including here the separation of Lophocebus from Cercocebus and their separate association with Papio and Mandrillus, respectively. We timed the splits and new associations to accord to the original species' branch lengths in Purvis (1995). With regard to family membership, we have largely followed Groves (2001) and, e.g., placed Callicebus within the Pitheciidae.

Analysis

Geographic sample We excluded Madagascar from global analyses. It covers such a small latitudinal extent that strong environmental, not latitudinal, influences on body 
mass are evident (Albrecht et al. 1990). Also, all the evidence indicates that Madagascar's primate community has suffered not only a more recent massive extinction than has any of the other continents, but also extinction of its largestbodied taxa (Godfrey et al. 1997). Its current complement of species is thus not as representative of the same evolutionary and ecological influences as for the other continents.

Taxonomic richness We described taxonomic diversity by a simple count of species whose mid-latitude lay within $5^{\circ}$ blocks, starting from $0-5^{\circ}$, and ending with a $15^{\circ}$ block from $25^{\circ}$ to $40^{\circ}$, and tested with the $G$ statistic via Statview SE+ (Abacus Concepts 1990-91), equivalent to the $\chi^{2}$ test. The wide latitudinal range of the last block was to ensure a sample of $>5$ species for statistical analysis, as well as to counteract the effect of decreasing area with increasing latitude. Strictly, a count of species is what ecologists term richness, but common English usage and the nature of the data mean that richness also corresponds to diversity.

Variance in mass We asked 2 main questions with regard to the data on latitudinal gradients in body mass. Does diversity (variance) of body mass change with latitude, and is there an overall trend in central value of body mass with latitude?

To ask the first question, we applied the Cook and Weisberg (1983) test of heteroscedasticity for a bivariate linear regression, using JMP 6.0 (SAS Institute Inc. 2005). The test in effect looks for a slope of magnitude of residuals of body mass by latitude against the original predictor (latitude): a steep slope indicates more change than does a shallow slope. Before testing for the slope, the residuals are squared to remove sign, and divided by the estimate of $\sigma^{2}$ as a means of scaling.

This test does not account for the drop in sample size across latitudes, and therefore leaves open the question of whether a detected decline in variance might be due merely to sample size as opposed to biological process. Various exact questions concerning the relationship between variance and mid-latitude as potentially determined by the sample size per latitude are possible. Was there a gradual change in variance with change in number of taxa? Was temperate variance less than equatorial variance? And so on. The last was the one we tested. It seemed to us that in the context, a useful question was whether the end points of the distribution, the extremes of the potential cline, were different. Given the nature of the data, if they were not, then we probably did not have a strong effect.

To test for the change of variance while at the same time accounting for sample size, we performed a nonparametric Wilcoxon test on the magnitude, sign removed, of residuals of body mass against latitude within equatorial and temperate latitudinal bands, via JMP 6.0 (SAS Institute Inc. 2005). This test is equivalent to a parametric anovar, but is more robust to the small high-latitude samples, and does not have the constraints of parametric tests. A nonsignificant Wilcoxon test statistic would suggest no evidence for differences in the magnitudes of residuals across latitudinal bands, whereas a significant test statistic would suggest genuine differences in residual magnitudes, accounting for unequal sample sizes at different latitudinal bands. We defined equatorial taxa as having a mid-latitude of $0-5^{\circ} \quad(N=73)$; temperate taxa had a mid-latitude of $>23^{\circ} 27^{\prime}(N=11)$. 
Central value of mass Regressions are common statistical analyses in latitudinal studies in macroecology, including the Bergmann effect. However, because, as will be seen, variance in the dependent variable ( $\log _{10}$ body mass of species) was not equal across the independent variable (mid-latitude of species), regressions are an invalid test, except with weighting to compensate for the change in variance. We therefore applied simple nonparametric Spearman correlations to test for change in central value of body mass.

Researchers have argued that in some analyses, especially those with map grid cells as the basis for analysis, body mass can vary with sample size (Meiri and Thomas 2007). To test for the effect of sample size on the relationship between latitude and central value of body size, we used the same statististical tests as we did for the relationship between variance and latitude, namely nonparametric Wilcoxon tests, comparing equatorial $\left(0-5^{\circ}\right)$ and temperate taxa $\left(>23^{\circ} 27^{\prime}\right)$.

Phylogenetic correction We corrected for phylogeny in investigation of the Bergmann effect in 2 ways. We analyzed at increasingly shallower taxonomic levels - order, family, genus - to investigate precisely within the deeper taxon where any effect exists. Throughout, we used comparative analysis by independent contrasts (CAIC 2.6.9; Purvis and Rambaut 1995) when analyses of the raw data showed a significant effect. The test in effect asks whether in pairs of related taxa the dependent measure consistently changes in the direction predicted, given a fitted positive contrast between the taxa in the independent measure (Purvis and Rambaut 1995).

We tested the CAIC results in 2 ways. One was a regression of contrasts of body mass on latitudinal contrasts. Here the question is whether larger contrasts in latitude are associated with larger contrasts in body mass. The CAIC program performs this test. The other means of testing was a Wilcoxon matched pairs $t$-test (SAS Institute Inc. 2005). With this test, the question is less refined: does the higher latitude taxon of a pair have a larger body mass than the lower latitude taxon, with no attention to amount of difference in latitude? As a further control on these tests, we recalculated after removal of the outlying nodes identified via CAIC; if a shallower outlier was nested within a deeper one, only the first was removed.

Accounting for continental width South and Central America are unusual in that taxonomic diversity is not highest near the equator, but rather near the greatest longitudinal width of the continent, i.e., ca. 5-10 ${ }^{\circ}$ (Ruggiero 1994; Ruggiero et al. 1998). Therefore, in addition to using real latitudes for the Americas in statistical tests, we treated this $5-10^{\circ} \mathrm{S}$ band as the equivalent of the $0-5^{\circ}$ band of Africa and Asia, offsetting all other latitudes for the continent by the requisite $5^{\circ}$. However, the results produced no change in either significance of differences, or gradients, and so we do not include them here.

Probability assessment We present 2-tailed probability values, and infer statistical significance from only them. 


\section{Results}

\section{Taxonomic and Morphological Diversity}

The mammalian order Primates is largely a tropical taxon, which means that its taxonomic diversity decreases dramatically with increasing latitude (Harcourt 2006; Pickford 1987). With mid-latitudes divided into $5^{\circ}$ blocks from $0-5^{\circ}$ to $25-40^{\circ}$ (the 3 high-latitude $5^{\circ}$-blocks lumped to ensure a sample of $>5$ species), the global distribution of numbers of species per block changes from 70 species at $0-5^{\circ}$ to 8 species at the highest-latitude block, $25-40^{\circ}\left(N\right.$ per $5^{\circ}$ latitudinal band: $70,44,15$, $13,14,8)$. The distribution is highly significantly different from an even distribution $(G=47.7, p=0.0001, \mathrm{df}=5)$. Latitudinal bands cover less area at higher latitudes, but the $25-40^{\circ}$ band is not less than one-eighth ( 8 vs. 70 species) the area of the $0-5^{\circ}$ band. In brief, primates show the Forster effect (Table 1).

Concomitantly with the reduction in taxonomic diversity with increasing latitude, variance of body mass also declines significantly as latitude increases (Figs. 1 and 2; Table 1). The decline is not evenly distributed across body sizes. Visual examination of the distribution of data indicates that the few very largest bodied taxa, all of them great apes, are closely confined to the equator. However, most of the latitudinal decrease in variance of body mass is due to the progressive disappearance of small-bodied taxa, which are effectively absent at the highest latitudes (Fig. 2). For instance, no species of the small-bodied (median mass, $0.25 \mathrm{~kg}$ ) suborder of strepsirrhines in Africa or Asia [bushbabies (Galagidae in Fig. 2), lorises] is extratropical, whereas several of the large-bodied (median $6.4 \mathrm{~kg}$ ) Old World catarrhine species ([monkeys (e.g., Cercopithecinae, Colobinae), apes] have extratropical mid-latitudes. This pattern of change of mass with latitude means that the body mass by latitude relationship in primates is triangular, not linear (Figs. 1 and 2).

The only continent that showed a significant change of variance in mass with mid-latitude was Asia. Africa and the Americas showed effectively no change (Table 1). However, Africa and the Americas had few species with high mid-

Table 1 Number of primate species and range and median of female body mass (kg) per species in equatorial $\left(0-5^{\circ}\right)$ and extratropical $\left(>23^{\circ} 27^{\prime}\right)$ latitudes (Equat., Ex-trop.) for globe and per continent to illustrate change with latitude of taxonomic richness (Forster effect), diversity of body mass, and overall body size (Bergmann effect)

\begin{tabular}{|c|c|c|c|c|c|c|}
\hline \multirow[t]{2}{*}{ Region } & \multicolumn{2}{|l|}{ Latitude } & \multicolumn{2}{|c|}{$0-5^{\circ}$ (equatorial) } & \multicolumn{2}{|c|}{$>23^{\circ} 27^{\prime}$ (extratropical) } \\
\hline & Equat. $N=$ & Ex-trop. $N=$ & Range & Median & Range & Median \\
\hline Globe & 70 & 11 & $0.06-71.5$ & 3.65 & $0.6-11.3$ & 9.5 \\
\hline Africa & 32 & 1 & $0.06-71.5$ & 3.6 & 11.0 & 11.0 \\
\hline Asia & 21 & 9 & $0.11-36.8$ & 5.9 & $4.95-11.3$ & 9.5 \\
\hline Americas & 17 & 1 & $0.4-8.4$ & 1.5 & 0.6 & 0.6 \\
\hline
\end{tabular}

Test of variance of body mass by latitude: globe: $\chi^{2}=4.45, \mathrm{df}=1, p<0.05$; Asia: $\chi^{2}=8.81$, $\mathrm{df}=1, p<0.01$; Africa, Americas: $\chi^{2}<1.0, p>0.1$ (Cook and Weisberg (1983) test of heteroscedasticity for a bivariate linear regression). Further statistical details are in Table 2. 
Fig. $1 \log _{10}$ median body mass females $\times$ mid-latitude of species. Calculated regression lines are for illustration only, because changing variance with latitude makes regression statistics invalid. $\square=$ Africa; $\mathrm{O}=$ Asia; $\Delta=$ Americas; - = Madagascar. Variance in body mass by latitude: globe: $\chi^{2}=$ $4.45, \mathrm{df}=1, p<0.05$ (excluding Madagascar); Asia: $\chi^{2}=8.81$, $\mathrm{df}=1, p<0.01$ (Cook and Weisberg (1983) test of heteroscedasticity for a bivariate linear regression). Other statistics are in Table 2.

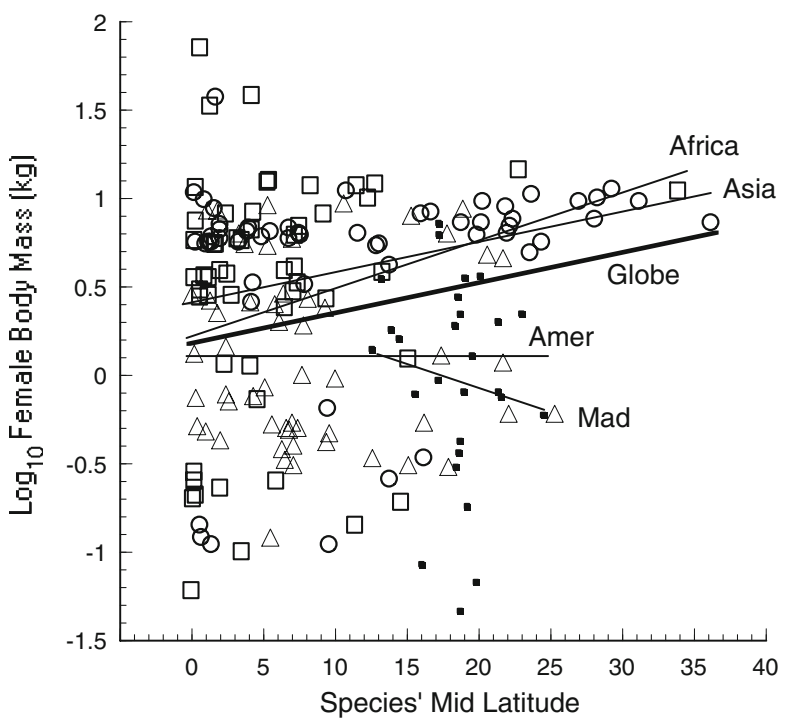

latitudes. For instance, only 3 (5\%) African species in 3 genera (Macaca, Otolemur, Papio), and 11 (20\%) American species in 4 genera (Alouatta, Aotus, Callithrix, Leontopithecus) had mid-latitudes of $>15^{\circ}$, whereas for Asia, $20(36 \%)$ species in 6 genera had such high mid-latitudes.

We added a nonparametric test of change of variance with latitude to account for the drop in sample size with latitude. Globally and in Asia, variance, measured as magnitude of residuals, dropped significantly with latitude: equatorial $\left(0-5^{\circ}\right)$ vs. nontropical $\left(>23.45^{\circ}\right)$ comparison, globe: $\chi^{2}{ }_{70,11}=7.15, \mathrm{df}=1, p<0.01$; Asia: $\chi_{21,9}^{2}=$ 12.94, $\mathrm{df}=1, p<0.001$; Wilcoxon test.

Fig. $2 \log _{10}$ median body mass females $\times$ mid-latitude of species showing only families/subfamilies with $\geq 10$ species. Open symbols indicate Old World taxa; solid symbols indicate New World. $\mathrm{O}=$ Cercopithecinae; $\square=$ Colobinae; $\Delta=$ Galagidae; $\diamond=$ Hylobatidae; $\bullet$ Atelidae; $\boldsymbol{x}=$ Pitheciidae; $\boldsymbol{\Delta}=$ Callitrichidae. Statistical details are in Tables 2 and 3.

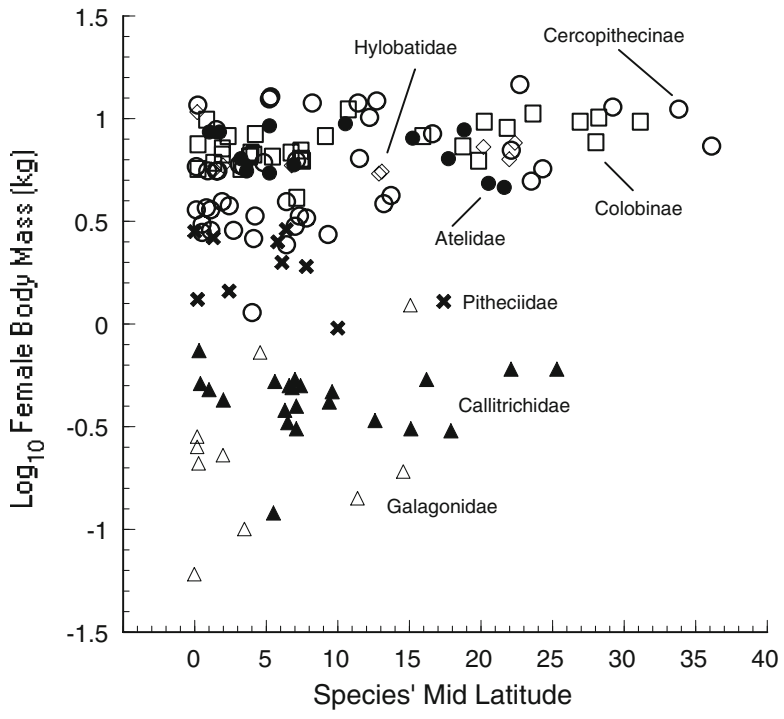


The Bergmann Effect

In presentation of the results in this section, we move from analysis of the whole order, Primates, through progressively shallower taxonomic levels to discover which taxa are most responsible for any apparent Bergmann effect.

Primates Globally, the body mass of the order Primates appeared to increase with increasing latitude (Fig. 1; Tables 1, 2, and 3). The effect existed with phylogeny controlled for by comparative analysis by independent contrasts (CAIC), though removal of outliers made one of the tests on the contrasts nonsignificant (Table 3). The continents differed in whether they showed the Bergmann effect: it was not apparent at all in the Americas, and was significant for a phylogenetically uncorrected analysis in Asia (Fig. 1; Tables 1 and 2). However, CAIC did not confirm the effect in Asia $(0.05<p<0.1$; Table 2a). The effect remained significant for both the globe and Asia, with sample size accounted for (Meiri and Thomas 2007) via nonparametric Wilcoxon tests $(z>2.12, p<0.05)$.

Catarrhini The order Primates is split into 3 major groups: the Platyrrhini of the Americas, and the Strepsirrhini (prosimians) and Catarrhini (monkeys and apes) of Africa and Asia, to the latter of which is related the single genus of the tarsiers. An obvious influence of taxonomy on the overall relationship was apparent: any Bergmann effect in the relationship was mostly due to the catarrhines (Old World monkeys and apes), which show a significant association of body mass with midlatitude globally and in Asia (Table 2a). We partly confirmed the Bergmann effect in the catarrhines globally and in Asia via CAIC (Table 3a), i.e., by regression analysis on the contrasts, but not convincingly by a Wilcoxon matched-pairs tests on them. For the globe, the effect remained significant with sample size taken into account $(z=2.27$, $p<0.025$ ), but not for Asia (Table 2a).

Cercopithecidae The catarrhines consist of Cercopithecidae (monkeys), Hylobatidae (gibbons), and the Hominidae (great apes). The Bergmann effect in the catarrhines was largely due to the Cercopithecidae. Globally, this family showed the effect significantly, including with phylogenetic control (Figs. 2 and 3; Tables 2b and 3b). The family occurred in both Africa and Asia. Though a significant Bergmann effect occurred in both continents, it remained significant after phylogenetic control in only Asia (Tables $2 \mathrm{~b}$ and $3 \mathrm{~b}$ ). The effect was significant globally and in Asia with sample size (species richness) accounted for $(z>2.1, p<0.05)$; we could not test the influence of sample size in Africa, because only 1 species in the sample was nontropical.

It seems likely that of all the families of Primates, only the cercopithecids showed the effect, in part because this family is the only one that extends substantially outside the tropics: while the highest mid-latitude of a noncercopithecid species is $25^{\circ}, 6$ cercopithecid species have higher mid-latitudes than this, the highest at $36^{\circ}$. Also, the cercopithecid sample was the largest: the family comprises 75 species in our sample, more than all the other primate families combined.

Cercopithecinae, Colobinae Cercopithecidae consists of the 2 subfamilies Cercopithecinae and Colobinae. Both showed the Bergmann effect globally (Table 2b). 


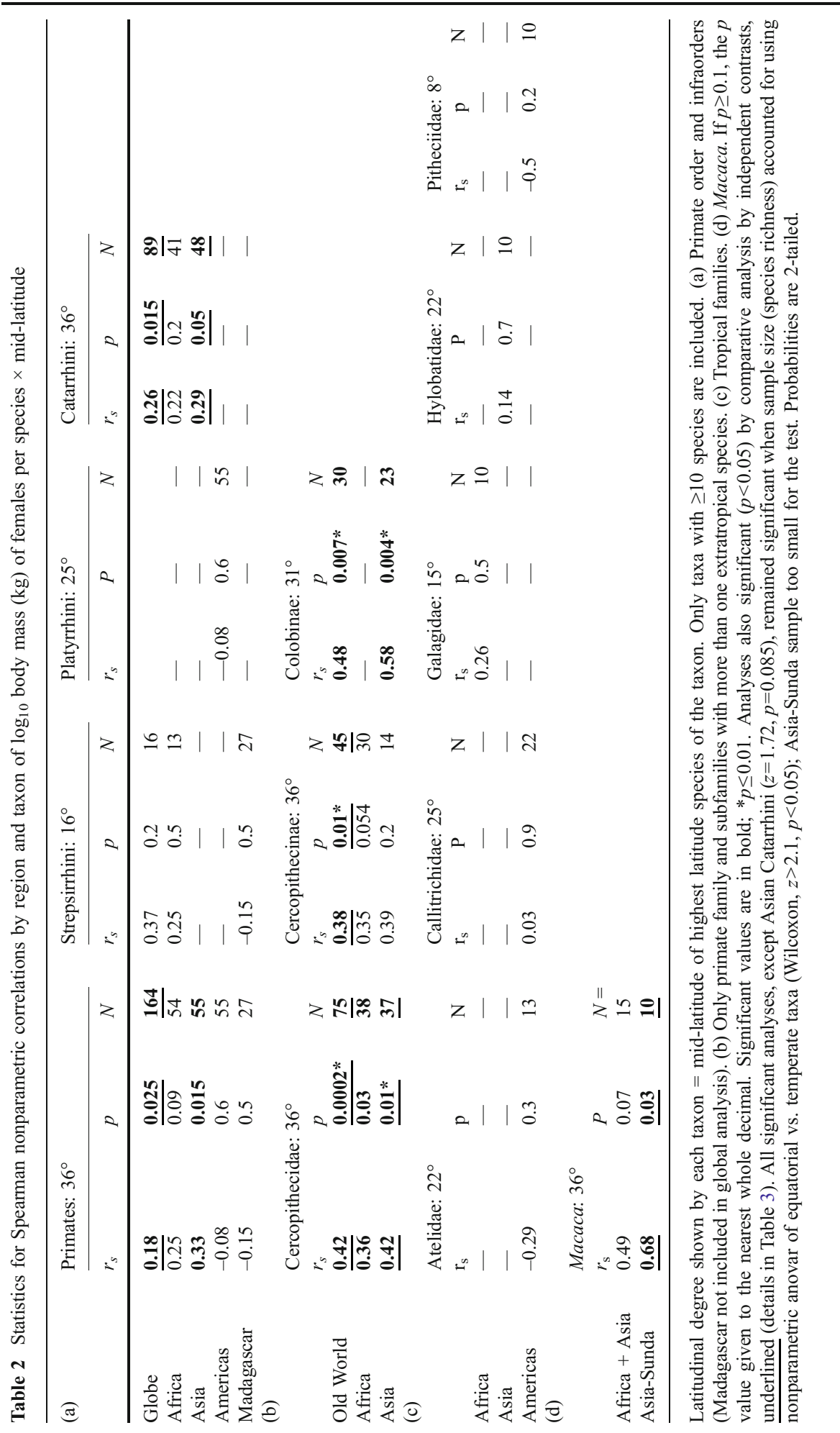




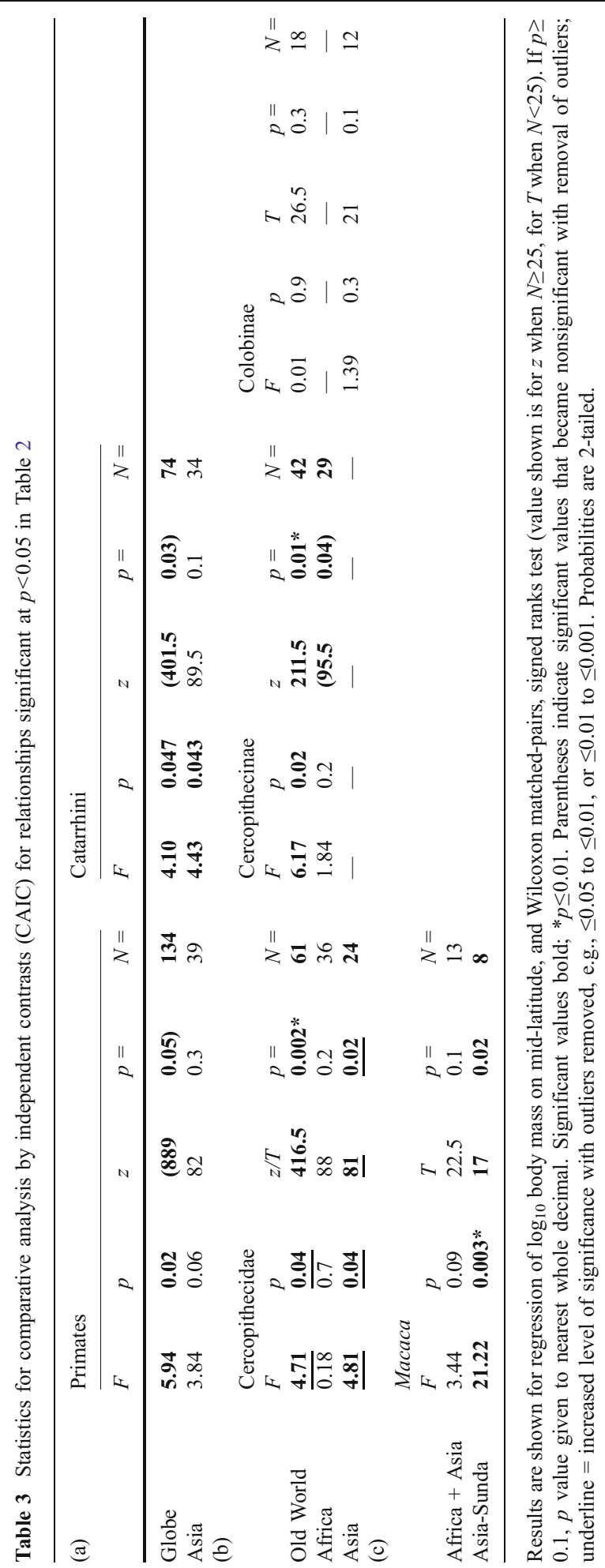


Fig. $3 \log _{10}$ median body mass females $\times$ mid-latitude of species of Cercopithecidae (heavy solid line), Cercopithecinae ( $O$, light solid line), Colobinae ( $\square$, light dashed line), and Macaca (inset:

- = mainland and continental island Asian species; $O=$ four Sulawesi species; $\mathrm{x}=1$ African species). Calculated regression lines in main figure are for illustration only, because changing variance with latitude makes regression statistics invalid; regression line in inset for mainland and continental island Asian species only. Statistical details are in Tables 2 and 3.

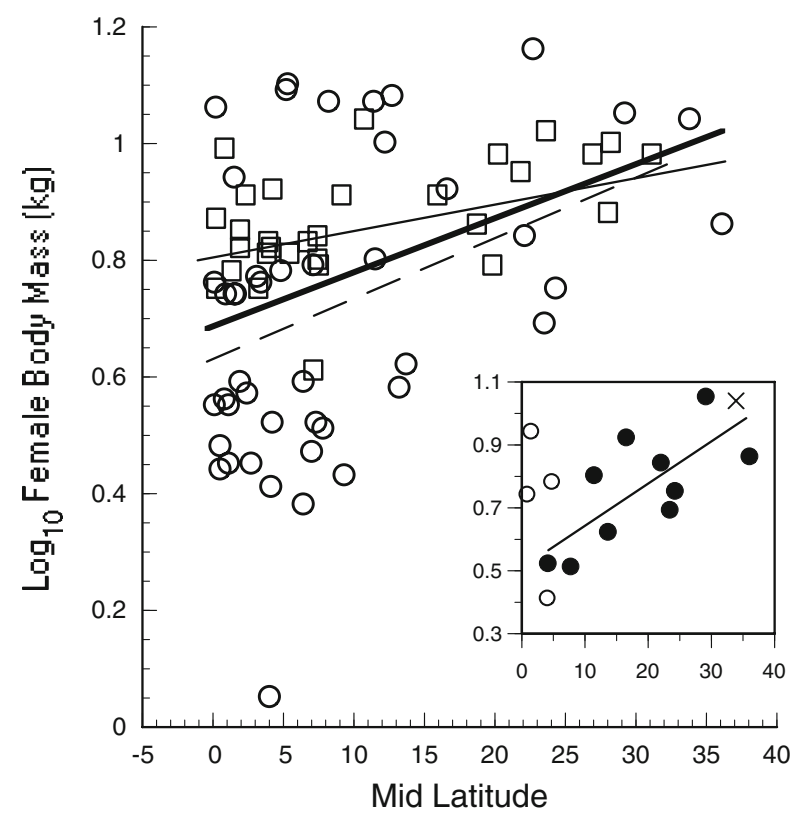

However, phylogenetic control confirmed the global effect in only the Cercopithecinae (Table 3b). Each subfamily occurs in both Africa and Asia. Whether a significant Bergmann effect was apparent within family-by-continent was equivocal, changing with the test performed (Table $2 b$ and $3 b$ ). For instance, without phylogenetic control, a significant Bergmann effect was apparent among Asian colobines (Table 2b), but this disappeared with CAIC (Table 3b). Sample size did not bias the effect, as indicated by continued significance in the nonparametric Wilcoxon test $(z>2.1, p<0.05)$.

The Asian colobine phylogenetic confound indicated by CAIC was obvious. Two of the 3 multispecies colobine genera show no overlap with each other in either body mass or mid-latitude: the genus with the species of smallest average body mass, Presbytis (median $6.5 \mathrm{~kg}$ ), occurs at the lowest latitudes (median $3.3^{\circ} \mathrm{N}$ ), whereas the largest-bodied genus, Rhinopithecus (median $9.9 \mathrm{~kg}$ ) occurs at the highest midlatitudes (median $28^{\circ} \mathrm{N}$ ). Therefore, between these 2 genera, effects of phylogeny cannot be separated from effects of biology.

By contrast, Trachypithecus overlaps species of Presbytis and Rhinopithecus in both mass and specific mid-latitude. It is thus a suitable genus to investigate the potential for the Bergmann effect across congeneric species. Though the raw association of mass with mid-latitude was positive $\left(r_{\mathrm{s}}=0.4\right)$, the relationship was not significant $(p>0.1)$.

However, phylogenetically, Trachypithecus is currently a very unsettled genus (Brandon-Jones et al. 2004). In our sample of 8 species of Trachypithecus, the taxon that we have termed T. johnii might in fact be Semnopithecus johnii (Brandon-Jones et al. 2004). Further, Trachypithecus phayrei might be a subspecies of T. obscurus (Brandon-Jones et al. 2004). If Trachypithecus johnii is omitted, and T. phayrei 
subsumed into T. obscurus, and their body masses and mid-latitude recalculated, there was some indication of a potential for a Bergmann effect in the genus $\left(r_{\mathrm{s}}=0.8\right.$, $p=0.08, N=6$ ).

Macaca The genus that provides the best opportunity for investigating the Bergmann effect at the level closest to the original formulation, that of congeneric species (Blackburn et al. 1999), is Macaca. It has the widest latitudinal extent of any genus (mid-latitudes of species from $1^{\circ}$ to $36^{\circ}$ ), and the most species in the sample $(N=15)$. The genus as a whole might show the Bergmann effect, but not convincingly (Fig. 3; Tables $2 \mathrm{~d}$ and $3 \mathrm{c}$ ). However, the macaques are a biogeographically heterogeneous genus. For instance, they are the only primate genus that occurs in both Africa and Asia: 1 species lives in Africa. Also, several of the species occur on islands, 4 of them on Sulawesi.

A sensible, biogeographically homogeneous subset within which to test for any Bergmann effect might be the macaques of mainland Asia and its continental islands, i.e., those connected to the mainland before their isolation by the Holocene rise in sea level, completed perhaps $6000 \mathrm{yr}$ ago (Voris 2000). This Asian and Sunda subset excludes Africa's single macaque species and the 4 Sulawesi species for which we have data. For this Asia-Sunda subset of Macaca, a significant Bergmann effect existed (Fig. 3; Table 2d), confirmed via CAIC (Table 3c). These results for female Macaca match Fooden's (Fooden 1971a, b) for males from the same region $\left(r_{\mathrm{s}}=\right.$ $0.67, p=0.07, N=8$ ). The sample was too small to test for an effect of sample size, but examination of Fig. 3 indicates a fairly even distribution of species of macaque across the latitudinal range of the genus.

To conclude with respect to the Bergmann effect, primates showed the common pattern for many relationships (Harvey and Clutton-Brock 1985) of more or less flat slopes across subtaxa (families, subfamilies), but an overall slope across the main taxon because, in this case, small-bodied taxa were essentially absent at high latitudes. Nevertheless, several subtaxa show the Bergmann effect, including with phylogenetic correction. The effect is shown by the suborder Catarrhini; the family Cercopithecidae; 1 of the 2 cercopithecid subfamilies, the Cercopithecinae; and 1 genus of one of these families, the Asia-Sunda Macaca. In sum, taxa that have the greatest latitudinal extension into temperate zones showed the Bergmann effect the most, and purely tropical taxa did not show it.

\section{Discussion}

The Pattern of Change with Latitude

In primates, variance of body mass and number of species start dropping with latitude from the equator, with account being taken of South America's greater geographical area $5-10^{\circ}$ south of the equator. The decrease in both measures mostly resulted from the absence of small-bodied clades at the highest latitudes. Otherwise, the body size of the larger primates stayed remarkably constant across the primates' global latitudinal distribution. Such is a general pattern: larger organisms often have lower slopes of mass against latitude than do smaller organisms (Brown and 
Nicoletto 1991; Cardillo 2002; Hillebrand 2004). The consequence for primates of the absence of small-bodied taxa at high latitudes was that the central value of body mass of primate species increased significantly with latitude.

This manifestation of the Bergmann effect across the primate order is different from that commonly occurring in shallower taxa, which is a more linear increase in body size with latitude. Nevertheless, it is what is expected if the Bergmann effect is produced by replacement of species, with larger-bodied instead of smaller-bodied taxa at higher latitudes (Blackburn et al. 1999; Cardillo 2002; Meiri and Thomas 2007). However, in the case of primates, the pattern was not replacement. Instead, larger-bodied forms and taxa occurred at all latitudes, whereas smaller bodied forms were confined to the tropics.

The Bergmann effect was also evident in some shallower clades, i.e., the family Cercopithecidae, its subfamilies, the Cercopithecinae and perhaps the Colobinae, and the cercopithecine genus Macaca. These shallower primate clades are the ones with the widest latitudinal extent within their taxonomic level. They all have mid-latitudes that span $>30^{\circ}$, by comparison to $\leq 25^{\circ}$ for any other taxon of the same level. This effect of latitudinal width is true of a wide range of taxa (Hillebrand 2004) and, e.g., mammalian carnivores (Meiri et al. 2007). The shallower primate clades are also the most speciose within their taxonomic level (cf. Hillebrand 2004). A wider latitudinal extent probably correlates with a greater variety of factors that might influence body size, and hence greater variation in body size with latitude, as well as greater likelihood of experiencing any single factor (Meiri et al. 2007; Rodríguez et al. 2006).

\section{The Process of Change with Latitude}

We suggest that the primate pattern of diminution in taxonomic and morphological diversity with latitude, along with the energy and heat retention/loss mechanisms often proposed for the Bergmann effect, might help to elucidate the processes by which the Forster effect occurs.

The greater taxonomic and also morphological diversity among primates in the tropics vs. higher latitudes, measured here as number of species and variance in body mass, respectively, matches general hypotheses about origination of diversity in the tropics. The latitudinal reduction in both taxonomic diversity and morphological diversity can be explained by hypotheses that advocate the operation of constraints on body form, and hence taxonomic diversity, at higher latitudes in taxa that show what has come to be termed niche conservatism. In other words, the Forster effect in at least primates exists, we suggest, because of a combination of origin of diversity in tropical climes, and constraints on diversity in extratropical climes (Fischer 1960; Pickford 1987), even if taxa do not always occur in latitudes or areas that are apparently climatically suitable (Currie et al. 2004).

The most obvious explanation for the drop in taxonomic diversity with latitude is simply that primates are confined to tropical forest. However, even if such restriction is part of the explanation, especially in South America, it is far from a sufficient explanation. The variety of taxa and of body sizes decreases as latitude increases from the equator, i.e., from well within the tropics and well within tropical forest. Further, the explanation begs the question of why primates might be so confined. In fact, primates are not confined to tropical forest, or even forest (Campbell et al. 
2007). Not only does the geographic range of $c a$. $20 \%$ of the species in this study extend outside the tropics, but several primate taxa occur in woodland, even open woodland, instead of forest; some primate species in Asia pass the winter in snowcovered conifer forest; and in Africa a baboon occurs in semidesert.

We have shown here that these extratropical taxa are not a random sample. None of the very large taxa, the great apes, have their mid-latitudes beyond $5^{\circ}$ from the equator; and starting from the equator, the higher the latitude the fewer small-bodied forms exist. We argue that the fact that it is mainly the larger-bodied forms, but not the very largest, that occur outside the tropics indicates both the operation of constraints on expansion of the primate order from the tropics, and also the nature of the constraints, i.e., the processes that produce the Bergmann effect. Explaining the Forster effect is not so much a question of explaining tropical diversity, we suggest, but of explaining constraints on dispersal outside the tropics.

The observed pattern of extremes apparently experiencing the most constraint outside the tropics would fit a hypothesis for the Bergmann effect in which the very largest-bodied taxa are unable to obtain enough total resources anywhere but the lowest latitudes (McNab 1999), while the smallest-bodied taxa are unable to persist over long periods of low temperature or resource shortage, or other extreme conditions, at the higher latitudes (Blackburn and Hawkins 2004; Lindstedt and Boyce 1985). Thus only the intermediate forms can expand from their latitude of origin, the tropics. This simple formulation can be seen as part of more general explanations of why medium sized forms do best in the long-run (Johst and Brandl 1997; Maurer 2003).

Debate occurs about whether the Bergmann effect applies more to small-bodied forms than to large-bodied forms (Ashton et al. 2000; Blackburn and Hawkins 2004). For primates, it seems that neither the very largest-bodied taxa nor the smaller-bodied taxa show the effect. An explanation is that they are so strongly affected by the thermodynamic influences that are hypothesized to cause the Bergmann effect that they cannot survive outside the tropics, and hence do not experience the energetic constraints that might produce the Bergmann effect. However, this cannot be the whole answer, given that the Bergmann effect seems to begin to operate from the equator, i.e., from well within the tropical latitudes.

The fact that the extratropical taxa are a subset of all the tropical taxa might indicate the operation of not an environmental constraint, but simply phylogenetic accident. However, primate subtaxa that show the Bergmann effect extend from the equator to outside the tropics. The existence of the Bergmann effect within these taxa allows us to infer that the lack of small-bodied taxa at high latitudes is due to the operation of the thermodynamic processes that seem to explain best the Bergmann effect; the effect is not due to phylogenetic accident, especially as with phylogeny controlled the Bergmann effect was confirmed in the primates as a whole and some of its subtaxa.

Direct evidence of primate taxa retreating in the face of cooling of the climate is available from sites of fossil recoveries (Jablonski 1998; Jablonski et al. 2000; Pickford 1987). For instance, Pongo (orangutan) reached ca. $35^{\circ} \mathrm{N}$ in Asia in the Pleistocene (Jablonski 1998; Jablonski et al. 2000), but the taxon's northern limit is now well within the tropics.

This analysis is not the last word on the topic for primates. We need, e.g., at the very least to consider correlates of body mass with the environmental factors relevant 
to the thermodynamic effects that might explain the Bergmann effect (Hawkins and Diniz-Filho 2004); we need to investigate whether an elevational Bergmann effect exists (Blackburn and Ruggiero 2001); and we need to consider other processes that might produce the Bergmann effect (Ferguson and Larivière 2008).

Finally, more than just body mass, and therefore more than just the Bergmann effect, must influence the ability of primates to extend outside the tropics. Even though the association of body mass with latitude was significant with phylogeny accounted for in our study, nevertheless, if some taxa in the 5-10 kg range of body mass can extend well outside the tropics, what prevents the others of similar body size from doing so? In Africa and Asia, terrestriality and the associated ability to inhabit woodland, as opposed to forest, correlates with macaques' extratropical midlatitudes, and the baboons' and vervets' ranging down to the Cape of southern Africa. So, why do not the baboons' more or less terrestrial relatives, the cercocebus mangabeys, not range into woodland, and hence outside the tropics? In addition, the colobines that range outside the tropics, especially Rhinopithecus, can use coniferous forest. If they can, why cannot more of the colobines?

Among primates and other taxa, the latitudinal extent of a taxon's geographic range is associated with both rarity and susceptibility to extinction (Harcourt 2006). That being the case, understanding of the traits in addition to body mass that allow primates to range widely will be important if we are to use biological knowledge to improve prospects for future persistence.

Acknowledgments We thank Mark Grote for statistical advice and Tim Blackburn, Howard Cornell, Mark Grote, Brad Hawkins, Mark Lomolino, and especially Shei Meiri for commentary that considerably improved the content and style of the paper.

Open Access This article is distributed under the terms of the Creative Commons Attribution Noncommercial License which permits any noncommercial use, distribution, and reproduction in any medium, provided the original author(s) and source are credited.

\section{References}

Abacus Concepts, I. (1990). Statview SE+. Berkeley, CA: Abacus Concepts, Inc., (1991).

Albrecht, G. H., Jenkins, P. D., \& Godfrey, L. R. (1990). Ecogeographic size variation among the living and subfossil prosimians of Madagascar. American Journal of Primatology, 22, 1-50. doi:10.1002/ ajp.1350220102.

Ashton, K. G., Tracy, M. C., \& de Queiroz, A. (2000). Is Bergmann's rule valid for mammals? American Naturalist, 156, 390-415. doi:10.1086/303400.

Blackburn, T. M., \& Gaston, K. J. (1996). Spatial patterns in the body sizes of bird species in the New World. Oikos, 77, 436-446. doi:10.2307/3545933.

Blackburn, T., \& Ruggiero, A. (2001). Latitude, elevation and body mass variation in Andean passerine birds. Global Ecology and Biogeography, 10, 245-259. doi:10.1046/j.1466-822X.2001.00237.x.

Blackburn, T., \& Hawkins, B. (2004). Bergmann's rule and the mammal fauna of northern North America. Ecography, 27, 715-724. doi:10.1111/j.0906-7590.2004.03999.x.

Blackburn, T., Gaston, K., \& Loder, N. (1999). Geographic gradients in body size: A clarification of Bergmann's rule. Diversity \& Distributions, 5, 165-174. doi:10.1046/j.1472-4642.1999.00046.x.

Brandon-Jones, D., Eudey, A. A., Geissmann, T., Groves, C. P., Melnick, D. J., Morales, J. C., Shekelle, M., \& Stewart, C. B. (2004). Asian primate classification. International Journal of Primatology, 25, 97-164. doi:10.1023/B:IJOP.0000014647.18720.32. 
Bromham, L., \& Cardillo, M. (2007). Primates follow the 'island rule': Implications for interpreting Homo floresiensis. Biology Letters, 3, 398-400. doi:10.1098/rsbl.2007.0113.

Brown, J. H., \& Nicoletto, P. F. (1991). Spatial scaling of species composition: Body masses of North American land mammals. American Naturalist, 138, 1478-1512. doi:10.1086/285297.

Campbell, C. J., Fuentes, A., MacKinnon, K. C., Panger, M., \& Bearder, S. K. (2007). Primates in perspective. New York: Oxford University Press.

Cardillo, M. (2002). Body size and latitudinal gradients in regional diversity of New World birds. Global Ecology and Biogeography, 11, 59-65. doi:10.1046/j.1466-822X.2001.00265.x.

Cook, R. D., \& Weisberg, S. (1983). Diagnostics for heteroscedasticity in regression. Biometrika, 70, 110. doi:10.1093/biomet/70.1.1.

Currie, D. J., Mittelbach, G. G., Cornell, H. V., Field, R., Guégan, J. F., Hawkins, B. A., Kaufman, D. M., Kerr, J. T., Oberdorff, T., O’Brien, E., et al. (2004). Predictions and tests of climate-based hypotheses of broad-scale variation in taxonomic richness. Ecology Letters, 7, 1121-1134. doi:10.1111/j.14610248.2004.00671.x.

ESRI Inc.(1998). ArcView GIS, 3.1. Environmental Systems Research Institute, Redlands, California.

Ferguson, S. H., \& Larivière, S. (2008). How social behaviour links environment and body size in mammalian carnivores. The Open Ecology Journal, 1, 1-7. doi:10.2174/1874213000801010001.

Fischer, A. G. (1960). Latitudinal variations in organic diversity. Evolution; International Journal of Organic Evolution, 14, 64-81. doi:10.2307/2405923.

Fooden, J. (1971a). Female genitalia and taxonomic relationships on Macaca assamensis. Primates, 12, 63-73. doi:10.1007/BF01730382.

Fooden, J. (1971b). Male external genitalia and systematic relationships of the Japanese macaque (Macaca fuscata Blyth 1875). Primates, 12, 305-311. doi:10.1007/BF01730417.

Forster, J. R. (1778). Excerpts from remarks on the organic bodies, Ch. 5 in Observations made during a voyage round the world. In M. V. Lomolino, D. F. Sax, \& J. H. Brown (Eds.), Foundations of biogeography pp. 19-27. Chicago: University of Chicago Press.

Gaston, K. J., Blackburn, T. M., \& Spicer, J. I. (1998). Rapoport's rule: Time for an epitaph? Trends in Ecology \& Evolution, 13, 70-74. doi:10.1016/S0169-5347(97)01236-6.

Gaston, K. J., Chown, S. L., \& Evans, K. L. (2008). Ecogeographical rules: Elements of a synthesis. Journal of Biogeography, 35, 483-500. doi:10.1111/j.1365-2699.2007.01772.x.

Godfrey, L. R., Jungers, W. J., Reed, K. E., Simons, E. L., \& Chatrath, P. S. (1997). Subfossil lemurs: Inferences about past and present primate communities in Madagascar. In S. M. Goodman, \& B. D. Patterson (Eds.), Natural change and human impact in Madagascar pp. 218-256. Washington, DC: Smithsonian Institution Press.

Green, J. L., Bohannan, B. J. M., \& Whitaker, R. J. (2008). Microbial biogeography: From taxonomy to traits. Science, 320, 1039-1043. doi:10.1126/science.1153475.

Groves, C. P. (1993). Order primates. In D. E. Wilson \& D. M. Reeder (Eds.), Mammal species of the world: a taxonomic and geographic reference pp. 243-277. Washington DC: Smithsonian Institution Press.

Groves, C. P. (2001). Primate taxonomy. Washington, DC: Smithsonian Institution Press.

Grubb, P., Butynski, T. M., Oates, J. F., Bearder, S. K., Disotell, T. R., Groves, C. P., \& Struhsaker, T. T. (2003). Assessment of the diversity of African primates. International Journal of Primatology, 24, 1301-1357. doi:10.1023/B:IJOP.0000005994.86792.b9.

Harcourt, A. H. (2000). Latitude and latitudinal extent: A global analysis of the Rapoport effect in a tropical mammalian taxon: Primates. Journal of Biogeography, 27, 1169-1182. doi:10.1046/j.13652699.2000.00482.x.

Harcourt, A. H. (2006). Rarity in the tropics: Biogeography and macroecology of the primates. Journal of Biogeography, 33, 2077-2087. doi:10.1111/j.1365-2699.2006.01557.x.

Harcourt, A. H., Coppeto, S. A., \& Parks, S. A. (2005). The distribution-abundance (i.e. density) relationship: Its form and causes in a tropical mammal order, Primates. Journal of Biogeography, 32, 565-579. doi:10.1111/j.1365-2699.2004.01214.x.

Harvey, P. H., \& Clutton-Brock, T. H. (1985). Life history variation in primates. Evolution; International Journal of Organic Evolution, 39, 559-581. doi:10.2307/2408653.

Hawkins, B. A., \& Diniz-Filho, J. A. F. (2004). 'Latitude' and geographic patterns in species richness. Ecography, 27, 268-272. doi:10.1111/j.0906-7590.2004.03883.x.

Hillebrand, H. (2004). On the generality of the latitudinal diversity gradient. American Naturalist, 163, 192-211. doi:10.1086/381004.

Jablonski, N. G. (1998). The response of catarrhine primates to Pleistocene environmental fluctuations in east Asia. Primates, 39, 29-37. doi:10.1007/BF02557741. 
Jablonski, N. G., Whitfort, M. J., Roberts-Smith, N., \& Qinqi, X. (2000). The influence of life history and diet on the distribution of catarrhine primates during the Pleistocene in eastern Asia. Journal of Human Evolution, 39, 131-157. doi:10.1006/jhev.2000.0405.

Johst, K., \& Brandl, R. (1997). Body size and extinction risk in a stochastic environment. Oikos, 78, 612617. doi: $10.2307 / 3545624$.

Lindstedt, A. L., \& Boyce, M. S. (1985). Seasonality, fasting endurance, and body size in mammals. American Naturalist, 125, 873-878. doi:10.1086/284385.

Maurer, B. A. (2003). Adaptive diversification of body size: the roles of physical constraint, energetics and natural selection. In T. M. Blackburn, \& K. J. Gaston (Eds.), Macroecology: concepts and consequences pp. 174-191. Oxford: Blackwell.

$\mathrm{McNab}, \mathrm{B}$. K. (1999). On the comparative ecological and evolutionary significance of total and massspecific rates of metabolism. Physiological and Biochemical Zoology, 72, 642-644. doi:10.1086/ 316701.

Meiri, S., \& Dayan, T. (2003). On the validity of Bergmann's rule. Journal of Biogeography, 30, 331-351.

Meiri, S., \& Thomas, G. H. (2007). The geography of body size - challenges of the interspecific approach. Global Ecology and Biogeography, 16, 689-693. doi:10.1111/j.1466-8238.2007.00343.x.

Meiri, S., Yom-Tov, Y., \& Geffen, E. (2007). What determines conformity to Bergmann's rule? Global Ecology and Biogeography, 16, 788-794. doi:10.1111/j.1466-8238.2007.00330.x.

Pickford, M. (1987). The diversity, zoogeography and geochronology of monkeys. Human Evolution, 2 , 71-89. doi:10.1007/BF02436532.

Purvis, A. (1995). A composite estimate of primate phylogeny. Philosophical Transactions of the Royal Society of London Series B, 348, 405-421. doi:10.1098/rstb.1995.0078.

Purvis, A., \& Rambaut, A. (1995). Comparative analysis by independent contrasts (CAIC): An Apple Macintosh application for analysing comparative data. Computer Applications in the Biosciences, 11, $247-251$.

Rodríguez, M. A., López-Sanudo, I. L., \& Hawkins, B. A. (2006). The geographic distribution of mammal body size in Europe. Global Ecology and Biogeography, 15, 173-181. doi:10.1111/j.1466822X.2006.00206.x.

Roy, K., Jablonski, D., \& Valentine, J. W. (2004). Beyond species richness: Biogeographic patterns and biodiversity dynamics using other metrices of diversity. In M. V. Lomolino, \& L. R. Heaney (Eds.), Frontiers of biogeography: New directions in the geography of nature pp. 151-169. Sunderland, MA: Sinauer Associates.

Ruggiero, A. (1994). Latitudinal correlates of the sizes of mammalian geographical ranges in South America. Journal of Biogeography, 21, 545-559. doi:10.2307/2845657.

Ruggiero, A., Lawton, J. H., \& Blackburn, T. M. (1998). The geographic ranges of mammalian species in South America: Spatial patterns in environmental resistance and anisotropy. Journal of Biogeography, 25, 1093-1103. doi:10.1046/j.1365-2699.1998.00253.x.

SAS Institute Inc.(2005). JMP 6.0. SAS Institute Inc., Cary, NC.

Shepherd, U. L. (1998). A comparison of species diversity and morphological diversity across the North American latitudinal gradient. Journal of Biogeography, 25, 19-29. doi:10.1046/j.13652699.1998.251172.x.

Smith, R. J., \& Jungers, W. L. (1997). Body mass in comparative primatology. Journal of Human Evolution, 32, 523-559. doi:10.1006/jhev.1996.0122.

Voris, H. K. (2000). Maps of Pleistocene sea levels in Southeast Asia: Shorelines, river systems and time durations. Journal of Biogeography, 27, 1153-1167. doi:10.1046/j.1365-2699.2000.00489.x. 